\title{
Abnormal coagulation and enhanced fibrinolysis due to lysinuric protein intolerance associates with bleeds and renal impairment
}

\section{Pitkänen, H. H.}

2018-09

Pitkänen , H H , Kärki , M , Niinikoski , H , Tanner , L , Näntö-Salonen , K , Pikta , M , Kopatz , W F , Zuurveld , M , Meijers , J C M , Brinkman , H J M \& Lassila , R 2018 , ' Abnormal coagulation and enhanced fibrinolysis due to lysinuric protein intolerance associates with bleeds and renal impairment ' , Haemophilia , vol. 24 , no. 5 , pp. E312-E321 . https://doi.org/10.1111/hae.13543

http://hdl.handle.net/10138/308858

https://doi.org/10.1111/hae.13543

publishedVersion

Downloaded from Helda, University of Helsinki institutional repository.

This is an electronic reprint of the original article.

This reprint may differ from the original in pagination and typographic detail.

Please cite the original version. 


\title{
Abnormal coagulation and enhanced fibrinolysis due to lysinuric protein intolerance associates with bleeds and renal impairment
}

\author{
H. H. Pitkänen ${ }^{1,2}$ (D) | M. Kärki ${ }^{3}$ | H. Niinikoski ${ }^{4}$ | L. Tanner ${ }^{5,6}$ | K. Näntö- \\ Salonen $^{3}$ | M. Pikta ${ }^{7}$ | W. F. Kopatz ${ }^{8}$ | M.Zuurveld ${ }^{9}$ | J.C. M. Meijers ${ }^{8,9}$ | \\ H. J. M. Brinkman ${ }^{9}$ | R. Lassila ${ }^{10,11}$ \\ ${ }^{1}$ Helsinki University Hospital Research Institute, Helsinki, Finland \\ ${ }^{2}$ Department of Anesthesiology, Intensive Care and Pain Medicine, University of Helsinki and Helsinki University Hospital, Helsinki, Finland \\ ${ }^{3}$ Department of Pediatrics, University of Turku, Turku, Finland \\ ${ }^{4}$ Department of Pediatrics and Physiology, University of Turku, Turku, Finland \\ ${ }^{5}$ Department of Medical Biochemistry and Genetics, University of Turku, Turku, Finland \\ ${ }^{6}$ Department of Clinical Genetics, Turku University Hospital, Turku, Finland \\ ${ }^{7}$ Northern Estonian Medical Center, Tallin, Estonia \\ ${ }^{8}$ Department of Experimental Vascular Medicine, Academical Medical Center, University of Amsterdam, Amsterdam, The Netherlands \\ ${ }^{9}$ Department of Plasma Proteins, Sanquin Research, Amsterdam, The Netherlands \\ ${ }^{10}$ Coagulation Disorders Unit, Department of Hematology, Comprehensive Cancer Center, University of Helsinki and Helsinki University Hospital, Helsinki, \\ Finland \\ ${ }^{11}$ Laboratory Services HUSLAB, University of Helsinki and Helsinki University Hospital, Helsinki, Finland
}

\section{Correspondence}

Riitta Lassila, Coagulation Disorders Unit, Department of Hematology and Comprehensive Cancer Center, Laboratory Services, Helsinki University Hospital, Helsinki, Finland.

Email: riitta.lassila@hus.fi

\section{Funding information}

Funding was received from Helsinki University Governmental Grant, The Finnish Society of Anaesthesiologists, Finnish Hematology Association, and Blood Disease Research Foundation.
Introduction: Lysinuric protein intolerance (LPI), a rare autosomal recessive transport disorder of cationic amino acids lysine, arginine and ornithine, affects intestines, lungs, liver and kidneys. LPI patients may display potentially life-threatening bleeding events, which are poorly understood.

Aims: To characterize alterations in haemostatic and fibrinolytic variables associated with LPI.

Methods: We enrolled 15 adult patients (8 female) and assessed the clinical ISTH/ SSC-BAT bleeding score (BS). A variety of metabolic and coagulation assays, including fibrin generation test derivatives, clotting time (CT) and clot lysis time (CLT), thromboelastometry (ROTEM), and PFA-100 and Calibrated Automated Thrombogram (CAT), were used.

Results: All patients had mild-to-moderate renal insufficiency, and moderate bleeding tendency (BS 4) without spontaneous bleeds. Mild anaemia and thrombocytopenia occurred. Traditional clotting times were normal, but in contrast, CT in fibrin generation test, and especially ROTEM FIBTEM was abnormal. The patients showed impaired primary haemostasis in PFA, irrespective of normal von Willebrand factor 
activity, but together with lowered fibrinogen and FXIII. Thrombin generation (TG) was reduced in vitro, according to CAT-derived endogenous thrombin potential, but in vivo TG was enhanced in the form of circulating prothrombin fragment 1 and 2 values. Very high D-dimer and plasmin- $\alpha 2$-antiplasmin (PAP) complex levels coincided with shortened CLT in vitro.

Conclusions: Defective primary haemostasis, coagulopathy, fibrin abnormality (FIBTEM, CT and CLT), low TG in vitro and clearly augmented fibrinolysis (PAP and D-dimer) in vivo were all detected in LPI. Altered fibrin generation and hyperfibrinolysis were associated with the metabolic and renal defect, suggesting a pathogenetic link in LPI.

KEYWORDS

coagulation disorder, fibrinolysis, lysinuric protein intolerance, thrombin generation

\section{1 | INTRODUCTION}

Lysinuric protein intolerance (LPI) is a rare autosomal recessive transport disorder of the cationic amino acids lysine, arginine and ornithine, affecting intestine, lungs, liver and renal tubules. ${ }^{1-4}$ Because of impaired intestinal absorption and tubular re-absorption in the kidney, plasma concentrations of lysine, arginine and ornithine are low in patients with LPI. A deficiency of arginine and ornithine restricts the function of the urea cycle and leads to hyperammonemia after dietary loads of protein. Lysine deficiency may influence the immune system and growth and may cause haematological abnormalities. Signs and symptoms of LPI include strong protein aversion in late infancy, failure to thrive, short stature, muscular weakness, osteoporosis and hepatosplenomegaly. Hypercholesterolemia, hypertriglyceridaemia and deficient B-cell function have also been reported. ${ }^{5-7}$ Renal insufficiency is a common complication associated with LPI that may progress to end-stage renal disease requiring renal transplantation. Severe pulmonary complications, including pulmonary fibrosis and alveolar proteinosis, may also occur. ${ }^{8-11}$ Several LPI patients with hemophagocytic lymphohistiocytosis syndrome $(\mathrm{HLH})$ have been reported in the literature. Serum ferritin is constantly markedly elevated in LPI patients, further referring to ongoing hemophagocytosis. ${ }^{12}$

Lysinuric protein intolerance is more prevalent in Finland (1 in 60000 ) than elsewhere in the world due to Finnish disease heritage, but several patients have been reported from, for example, Italy, Tunisia, and Japan. ${ }^{13,14}$ LPI is caused by bi-allelic mutations in the gene SLC7A7, which encodes the $\mathrm{y}^{+}$LAT1 protein, the catalytic light chain subunit of the heteromeric amino acid transporter. ${ }^{15-18}$ All the Finnish patients share the same mutation, a substitution of $T$ for $A$ at

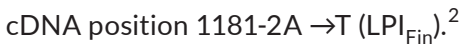

It has been recognized that LPI patients may display bleeding events. Even fatal haemorrhage has been observed postpartum and otherwise, but the mechanisms rendering the LPI patients prone to bleeding are unknown, although low platelet counts, low fibrinogen, high D-dimer and elevated levels of thrombin-antithrombin complex (TAT) have been observed. ${ }^{19,20}$ The prevalence and pathogenesis of coagulopathy associated with LPI has not been systemically evaluated, and case reports on this subject are sparse. The aim of this study was to characterize alterations in haemostatic and fibrinolytic markers in LPI patients compared with controls and the renal impairment. The motivation for this study is the unmet need to guide the perioperative management of these patients in general, specifically during renal transplantation.

\section{2 | METHODS}

\section{1 | Subjects}

The diagnostics and annual follow-up of Finnish LPI patients is centralized to the Department of Pediatrics at the Turku University Hospital. The current study cohort consisted of 15 adult LPI patients (8 women) available for analysis. The median age of the participants was 45 years (ranging 23-60 years). Our study was approved by the ethics committee of Turku University Hospital, and informed consent was obtained in accordance with the Declaration of Helsinki. Eleven of the patients used lysine supplementation. One patient had regular dipyridamole/acetylsalicylic acid medication due to a history of a transient ischaemic attack. One patient had previously undergone a splenectomy, and another had both a kidney transplant and splenectomy. At the time of the study, one patient had developed end-stage renal disease and needed regular erythropoietin injections to treat renal anaemia. Control plasma was collected from nonmatched volunteer donors in the same age range as our LPI patients. All volunteers had normal body mass index, no known illnesses, medications nor any history of bleeds.

\subsection{Sample collection}

Blood samples were collected in citrate anticoagulant $(109 \mathrm{mmol} / \mathrm{L}$ sodium citrate) from the patients and healthy volunteers. Platelet-poor 
plasma (PPP) was processed by centrifugation at $2500 \mathrm{~g}$ for 15 minutes at room temperature. PPP was stored in aliquots at $-80^{\circ} \mathrm{C}$.

\section{3 | LPI routine follow-up}

All LPI patients were clinically examined (weight, blood pressure), including routine follow-up metabolic assays: total blood cell count, plasma ferritin, plasma alanine aminotransferase (ALT), plasma creatinine (P-Crea), urinary creatinine ( $\mathrm{U}-\mathrm{Crea}$ ), serum cystatin $\mathrm{C}$, urine beta2-microglobulin for an early marker of renal insufficiency, plasma and urinary amino acids, including plasma lysine (P-LYS) and urinary lysine (U-LYS), plasma ammonia $\left(\mathrm{P}-\mathrm{NH}_{4}\right)$, total plasma cholesterol, low-density lipoprotein (LDL), high-density lipoprotein (HDL), triglycerides, plasma prealbumin, and capillary blood gas analysis. To estimate the glomerular filtration rate (eGFR), the Chronic Kidney Disease Epidemiology Collaboration (CKD-EPI) equation was used. ${ }^{21}$ Urinary lysine levels without creatinine correction were calculated by multiplying U-LYS with U-Crea.

\subsection{Clinical evaluation of bleeding tendency}

The ISTH/SSC-BAT questionnaire ${ }^{22}$ for scoring the severity of the bleeding tendency was used to evaluate the clinical impact of LPI on haemostasis. Normal values of this bleeding score (BS) for men are $<4$ points and $<6$ points for women. ${ }^{23}$

\subsection{Coagulation biomarkers and primary hemostasis PFA-100}

The following routine coagulation assays were used: blood cell count, prothrombin time (PT, Nycotest PT, Axis-Shield PoC As, Oslo, Norway), activated partial thromboplastin time (APTT, Actin FSL, Siemens Healthcare Diagnostics, Erlangen, Germany), thrombin time (TT) (BC Thrombin reagent, Siemens Healthcare Diagnostics) and von Willebrand factor activity (VWF:Ac) assay (INNOVANCE VWF Ac., Siemens Healthcare Diagnostics). Primary hemostasis was studied with either epinephrine (EPI) or adenosine-5-diphosphate (ADP) and recorded as closure times of collagen membrane cartridges in the PFA-100 (Siemens Healthcare Diagnostics).

Also, FXIII:C activity (Berichrom chromogenic FXIII, Siemens Healthcare Diagnostics), fibrinogen (modified Clauss method, Multifibren U, Siemens Healthcare Diagnostics), D-dimer (immunoturbidometric Tina-quant D-Dimer, Roche Diagnostics, Mannheim, Germany), plasminogen and $\alpha 2$-antiplasmin (Diagnostica Stago S.A.S. Asnières sur Seine, France), F1 + 2 (Enzygnost monoclonal, Siemens Healthcare Diagnostics), plasmin $\alpha 2$-antiplasmin complex (PAP) micro Elisa (DRG Diagnostica, Marburg, Germany) and TAFI activity (PEFA kit, Pentapharm, Basel, Switzerland) were assessed.

\section{6 | ROTEM}

Thromboelastometric variables were studied with a ROTEM device (TEM International $\mathrm{GmbH}$, Munich, Germany) at $37^{\circ} \mathrm{C}$ in citrated whole blood according to the manufacturer's instructions. ROTEM tracings were recorded up to 60 minutes. EXTEM uses TF as an activator and explores extrinsic pathway, and INTEM is activated by phospholipids and ellagic acid, mimicking intrinsic pathway. Both EXTEM and INTEM are influenced by platelets and fibrinogen. FIBTEM is a modification of EXTEM, showing the isolated effect of fibrinogen under cytochalasin D-induced platelet inhibition. Clotting time (CT s), clot formation time (CFT s), clot formation after $10 \mathrm{~min}$ utes (A10 mm), maximum clot firmness (MCF $\mathrm{mm}$ ) and maximum lysis (ML \%) were collected. Further details about thromboelastometry are described elsewhere. ${ }^{24}$

\subsection{Calibrated Automated Thrombogram (CAT)}

Thrombin generation (TG) was measured in vitro with CAT (Labscan, Thermo Fisher, Helsinki, Finland) assay using the Thrombinoscope software (Thrombinoscope, Maastricht, The Netherlands) and reagents (Diagnostica Stago, Asnières sur Seine Cedex, France), in the absence of corn trypsin inhibitor and according to the manufacturer's instructions. ${ }^{25} \mathrm{~A}$ reaction was triggered with $1 \mathrm{pM}$ TF and $4 \mu \mathrm{mol} / \mathrm{L} \mathrm{PL}$ (PPP reagent low). The CAT variables included lag time (time to initiation of thrombin formation, minute), endogenous thrombin potential (ETP; the area under the curve; $\mathrm{nmol} / \mathrm{L}$ thrombin $\times \mathrm{min}$ ) and peak (maximum thrombin concentration, $\mathrm{nmol} / \mathrm{L})$.

\section{8 | Fibrin generation and clot lysis test}

To assess fibrin generation and clot lysis, optical density (OD) of clotting plasma, triggered with TF, was measured in the presence of tissue plasminogen activator (tPA) to induce fibrinolysis. Carboxypeptidase inhibitor (Sigma Aldrich St. Louis, MO, USA) was included in parallel incubations to inhibit activated thrombin-activatable fibrinolysis inhibitor (TAFla). Typically, $75 \mu \mathrm{L}$ plasma was mixed with $75 \mu \mathrm{L}$ trisbuffered saline containing the carboxypeptidase inhibitor when indicated and start reagents (TF, phospholipids, tPA and $\mathrm{CaCl}_{2}$ at final concentrations of $0.5 \mathrm{pmol} / \mathrm{L}, 4 \mu \mathrm{mol} / \mathrm{L}, 50 \mathrm{ng} / \mathrm{mL}$, and $15 \mathrm{mmol} / \mathrm{L}$, respectively). ODmax was derived directly from the OD tracing measured at $405 \mathrm{~nm}$. For clotting time (CT) and clot lysis time (CLT) measurements, the first derivative of the OD tracing was used. CT is defined as the time from start reagent addition to maximal rate of fibrin generation (first peak in the plot time against first derivative OD). CLT is defined as the time between the maximal rate of fibrin generation and the maximal rate of clot lysis (second peak in the first derivative plot).

\section{9 | Statistics}

The median and the range were calculated and reported for all measurements. The Shapiro-Wilk normality test was performed. Groups were compared using the Mann-Whitney test. Correlations were calculated with the Spearman correlation coefficient, also using linear regression models where pertinent. IBM SPSS Statistics 22 was 
used to calculate statistics, and $P$-values $<.05$ were considered statistically significant.

\section{3 | RESULTS}

\section{1 | Bleeding score}

Nine patients presented with normal BS. Six patients had elevated BS (Table 1), and three of them were women. Median BS for women was 5 (range 0-9), and for men 2 (range -1-6) points. Two of the three women had experienced severe postpartum haemorrhage. Besides labour, one of these two women also bled during a splenectomy due to abdominal trauma and kidney transplant surgery. The third woman had menorrhagia combined with mucocutaneous bleeds. One man bled after a splenectomy due to spontaneous cyst rupture, the other had gastrointestinal (GI) haemorrhage and the third had multiple mucocutaneous bleeds related to dental procedures. In general, most common bleeding manifestations occurred from minor wounds, oral cavity, after tooth/teeth extraction, after surgery or major trauma, menorrhagia and postpartum haemorrhage. Two women had normal labour and puerperium, and one man underwent minor surgery without bleeding complications. Other seven patients were not subjected to surgical procedures. No muscle hematomas, haemarthrosis nor other spontaneous bleeds, except for the one $\mathrm{Gl}$ bleed, were reported. Ten patients had both mild anaemia and iron substitution (Table 1).

\subsection{Routine clinical chemistry analyses}

The plasma levels of ALT were moderately elevated in three patients, as was $\mathrm{NH}_{4}$ (up to $62 \mu \mathrm{mol} / \mathrm{L}$ ) in four patients, but prealbumin was normal in all, excluding major liver impairment in our patients. Eleven patients had elevated plasma creatinine concentration, and 12 patients had reduced eGFR. Urinary creatinine (U-crea) measured from 12 patients was normal. Serum cystatin $C$ was also elevated in 10 patients. Only one patient had normal urine beta2-microglobulin, while it was elevated in all others. P-LYS was reduced in four patients, and U-LYS was high in all 12 with the measurement available. Capillary blood gas analysis in 13 patients showed normal pH in 7, whereas only three presented with normal base excess, and five patients had a normal bicarbonate level (Table 2).

Hyperlipidaemia was common, especially hypertriglyceridaemia. Most patients (10/12) had elevated total cholesterol. LDL was measured in 12 patients, but only 4 had normal levels. Five patients had normal but the rest had low HDL. Moreover, 12 patients had combined hyperlipidaemia, while only 3 patients had normal

TABLE 1 ISTH-BAT bleeding score

\begin{tabular}{|c|c|c|c|c|c|c|c|c|c|c|c|c|c|c|c|c|}
\hline & 1 & 2 & 3 & 4 & 5 & 6 & 7 & 8 & 9 & 10 & 11 & 12 & 13 & 14 & 15 & Cumulative \\
\hline Sex & W & W & $M$ & W & W & $M$ & W & $M$ & $M$ & W & $M$ & W & $M$ & $M$ & W & \\
\hline Age & 40 & 48 & 49 & 23 & 34 & 60 & 29 & 52 & 23 & 45 & 46 & 51 & 40 & 43 & 48 & \\
\hline Epistaxis & 0 & 0 & 0 & 0 & 0 & 0 & 0 & 0 & 0 & 1 & 0 & 0 & 0 & 0 & 0 & 1 \\
\hline Cutaneous bleeding & 1 & 1 & 0 & 1 & 0 & 3 & 1 & 0 & 0 & 0 & 1 & 1 & 0 & 1 & 0 & 10 \\
\hline $\begin{array}{l}\text { Bleeding from minor } \\
\text { wounds }\end{array}$ & 0 & 0 & 0 & 1 & 0 & 0 & 0 & 0 & 0 & 2 & 0 & 1 & 0 & 0 & 0 & 4 \\
\hline Oral cavity bleeding & 1 & 0 & 0 & 1 & 1 & 0 & 0 & 0 & 1 & 1 & 1 & 0 & 1 & 1 & 0 & 8 \\
\hline $\begin{array}{l}\text { Bleeding after Tooth/ } \\
\text { Teeth extraction }\end{array}$ & 3 & 0 & -1 & 0 & 2 & 0 & 0 & 0 & -1 & 3 & 3 & -1 & 3 & 0 & 0 & 11 \\
\hline $\begin{array}{l}\text { Gastrointestinal } \\
\text { bleeding }\end{array}$ & 0 & 0 & 0 & 0 & 0 & 0 & 0 & 0 & 0 & 0 & 2 & 0 & 0 & 0 & 0 & 2 \\
\hline $\begin{array}{l}\text { Bleeding after } \\
\text { Surgery or Major } \\
\text { trauma }\end{array}$ & 0 & 0 & 0 & 0 & 0 & 0 & 0 & 4 & 0 & 0 & 0 & 2 & 0 & 0 & 0 & 6 \\
\hline $\begin{array}{l}\text { Muscle hematomas } \\
\text { (spontaneous) }\end{array}$ & 0 & 0 & 0 & 0 & 0 & 0 & 0 & 0 & 0 & 0 & 0 & 0 & 0 & 0 & 0 & 0 \\
\hline Haemarthrosis & 0 & 0 & 0 & 0 & 0 & 0 & 0 & 0 & 0 & 0 & 0 & 0 & 0 & 0 & 0 & 0 \\
\hline Anaemia & + & + & & + & + & & + & + & & + & & + & & + & + & 10 \\
\hline Iron substitution & + & + & & + & + & & + & + & & + & & + & & + & + & 10 \\
\hline $\begin{array}{l}\text { Family history of } \\
\text { bleeds }\end{array}$ & + & + & & & & + & & + & & & & & & & + & 5 \\
\hline Menorrhagia & 0 & 0 & & 2 & 2 & & 0 & & & 2 & & 2 & & & 3 & 11 \\
\hline $\begin{array}{l}\text { Postpartum } \\
\text { haemorrhage }\end{array}$ & 3 & -1 & & & & & & & & 0 & & 3 & & & & 5 \\
\hline Cumulative & 8 & 0 & -1 & 5 & 5 & 3 & 1 & 4 & 0 & 9 & 7 & 8 & 4 & 2 & 3 & \\
\hline
\end{tabular}

W, women; M, men. 
triglycerides. Ten patients had cholesterol medication (simvastatin), but only one patient had normal cholesterol values without medication. Four patients reached normal LDL levels with their medication, whereas six remained hypercholesterolemic (Table 2).

\section{3 | Blood cell counts, PFA-100, coagulation activity and D-dimer}

Median haemoglobin in women was $123 \mathrm{~g} / \mathrm{L}$ (range 109-137 g/L) and $131 \mathrm{~g} / \mathrm{L}$ in men (ranging 106-147 g/L). Six presented with mild thrombocytopenia. White blood cell count was normal, whereas plasma ferritin levels were high in all patients (Table 3). Although none of the patients had the diagnosis of $\mathrm{HLH}, 11 / 15$ patients met 3 of its 8 diagnostic criteria, ${ }^{26}$ of which 5 would indicate HLH. These observations included splenomegaly, hypertriglycerideamia or hypofibrinogenemia and ferritin levels exceeding $500 \mu \mathrm{g} / \mathrm{L}$. PT, APTT, and TT and VWF:Ac were all normal (Table 3). However, despite the normal VWF:Ac, only four patients had normal PFA closure time in the epinephrine cartridge, being prolonged among the others (Table 3). ADP closure time was measured for 11 patients, all showing prolongation, coinciding with the prolonged EPI closure times. Platelet count and EPI closure time correlated $(r=-.55 ; P=.03)$, whereas the platelet count did not correlate with ADP closure time or VWF:Ac levels (Table S1 on the individual platelet counts and PFA-100 results).

Functional fibrinogen level was low, although in the normal range, but four patients exhibited fibrinogen below $1.7 \mathrm{~g} / \mathrm{L}$ without prolonged thrombin time (Table 3). Median FXIII:C was also low, and only four patients had FXIII:C activity within the reference range

\begin{tabular}{|c|c|c|c|c|}
\hline Variable & $\begin{array}{l}\text { Metabolic and renal } \\
\text { markers }\end{array}$ & \multicolumn{2}{|c|}{ Reference range } & LPI patients \\
\hline \multicolumn{5}{|l|}{ Hepatic markers } \\
\hline \multirow[t]{2}{*}{ ALT } & \multirow[t]{2}{*}{ Plasma (U/mL) } & W: & $<35$ & $28(15-34)$ \\
\hline & & M: & $<50$ & $38(20-150)$ \\
\hline $\mathrm{NH}_{4}$ ion & Plasma ( $\mu \mathrm{mol} / \mathrm{L})$ & & $<50$ & $37(16-62)$ \\
\hline Prealbumin & Serum (g/L) & & $0.2-0.4$ & $0.3(0.2-0.4)$ \\
\hline \multicolumn{5}{|l|}{ Renal markers } \\
\hline \multirow[t]{2}{*}{ Creatinine } & \multirow[t]{2}{*}{ Plasma ( $\mu \mathrm{mol} / \mathrm{L})$} & W: & $50-90$ & $128(68-201)$ \\
\hline & & M: & $60-100$ & $186(76-362)$ \\
\hline \multirow[t]{2}{*}{ Creatinine } & \multirow[t]{2}{*}{ Urine (mmol/L) } & W: & $1.7-19.4$ & $5.3(3.0-8.5)$ \\
\hline & & M: & $2.3-23.5$ & $8.1(1.9-15.8)$ \\
\hline Cystatin C & Serum (mg/L) & & $0.6-1.1$ & $1.4(0.6-2.5)$ \\
\hline $\begin{array}{l}\text { Beta2- } \\
\text { microglobulin }\end{array}$ & Urine (mg/L) & & $0-0.3$ & $19.2(0.05-97)$ \\
\hline $\begin{array}{l}\text { eGFR }(\mathrm{mL} / \mathrm{min} / \\
\left.\mathrm{m}^{2}\right)\end{array}$ & & & & $44(16-105)$ \\
\hline LYS & Plasma ( $\mu \mathrm{mol} / \mathrm{L})$ & & $114-289$ & $132(69-172)$ \\
\hline LYS & $\begin{array}{c}\text { Urine ( } \mu \mathrm{mol} / \\
\text { mmolCrea) }\end{array}$ & & $2-63$ & $406(112-1076)$ \\
\hline \multicolumn{5}{|l|}{ Lipids } \\
\hline Total cholesterol & Plasma (mmol/L) & & $<5$ & $5.8(3.8-8.6)$ \\
\hline LDL & Plasma (mmol/L) & & $<3$ & $3.5(2.0-4.4)$ \\
\hline \multirow[t]{2}{*}{$\mathrm{HDL}$} & \multirow[t]{2}{*}{ Plasma (mmol/L) } & W: & $>1.2$ & $1.2(1.1-1.4)$ \\
\hline & & M: & $>1.0$ & $1.1(0.5-1.3)$ \\
\hline Triglycerides & Plasma (mmol/L) & & $<2.0$ & $2.6(0.9-7.1)$ \\
\hline Capillary blood gas & Blood & & $7.35-7.45$ & $7.35(7.26-7.42)$ \\
\hline \multicolumn{5}{|l|}{$\mathrm{pH}$} \\
\hline $\mathrm{pCO}_{2}(\mathrm{kPa})$ & & & $4.5-6.0$ & $4.8(3.1-7.7)$ \\
\hline $\mathrm{BE}(\mathrm{mmol} / \mathrm{L})$ & & & $-2.5-+2.5$ & $-4.2(-10.5$ to -1.3$)$ \\
\hline $\begin{array}{l}\text { Bicarbonate } \\
\text { (mmol/L) }\end{array}$ & & & $22-26$ & $21(13-23)$ \\
\hline
\end{tabular}

TAB LE 2 Routine metabolic and renal follow-up

ALT, alanine aminotransferase; $\mathrm{NH}_{4}$, ammonium; eGFR, estimated glomerular filtration rate; LYS, lysine; LDL, low-density lipoprotein; HDL, high-density lipoprotein; BE, base excess; W, women; M, men. Data for LPI patients are given as median (range).

Reference range for eGRF: age 18-39 years $>89,40-49$ years $>83,50-59$ years $>77,60-69$ years $>69$. 
(Table 3). However, the most striking and uniform finding was the elevated D-dimer level in all patients (Table 3, individual fibrinogen, FXIII and D-dimer in Table S1).

\subsection{In vitro and in vivo thrombin generation}

In vitro thrombin generation (TG), as determined by the TF-triggered CAT, was partially impaired compared with healthy controls. Lag time (Figure 1A) and peak TG (Figure 1B) did not differ from healthy controls. However, ETP was significantly reduced in $\operatorname{LPI}(P=.02)$ (Figure 1C). In contrast, circulating biomarker F1 + 2 implied strong in vivo TG (Table 3), as it exceeded 1200 (range 961 - >1200) pmol/L. In healthy individuals, the F1 + 2 median was 178 (range 91-272) pmol/L.

\section{5 | In vitro fibrin clot formation}

In ROTEM, some variables differed from normal in LPI patients. As expected, FIBTEM MCF recognized fibrinogen levels below the reference range (Table 3). In addition, seven patients had decreased FIBTEM MCF, beyond the four with fibrinogen level $<1.7 \mathrm{~g} / \mathrm{L}$ (Table 3). Besides low fibrinogen, low FXIII:C levels may contribute to FIBTEM MCF, and indeed, FXIII:C showed correlation with FIBTEM MCF ( $r=.63, P=.01)$. INTEM CT was normal, but six patients showed prolonged CFT, and four displayed declined MCF. EXTEM CT and CFT were prolonged in seven patients, and MCF was reduced in five. All EXTEM variables and INTEM CFT, A10 and MCF correlated significantly with fibrinogen levels, but not with platelet counts. Both INTEM and EXTEM ML were within reference ranges (Table 4). Fibrin clot formation triggered with low TF and was traced by ODmax measurement, revealing a median $C T$ that was significantly prolonged in LPI compared to controls $(P<.001)$ (Figure 1E). The median ODmax was decreased in LPI $(P=.03)$ (Figure 1D).

\section{6 | Fibrinolysis}

As a sign of enhanced in vivo fibrinolysis, together with D-dimer, circulating PAP levels were also extremely high, exceeding $2000 \mu \mathrm{g} / \mathrm{L}$ and the calibration curve range. In healthy individuals, the median PAP was $638 \mu \mathrm{g} / \mathrm{L}$ (range 430-862 $\mu \mathrm{g} / \mathrm{L}$ ). In comparison with healthy controls, median plasminogen was elevated $(P=.01)$ (Figure $2 A)$, while $\alpha 2$-antiplasmin levels were lower $(P<.001)$ (Figure $2 B)$. This resulted in clearly higher plasminogen/ $\alpha 2$-antiplasmin ratio (median 1.50; range 1.10-2.02) than in healthy controls (0.96; range 0.82 1.16) $(P<.001)$ indicating increased fibrinolytic capacity in LPI. TAFI levels were slightly reduced in 5 patients (Table 3 ). Again, compatible with enhanced fibrinolysis in general, LPI patients showed shorter $\mathrm{CLT}(P<.01)$ (Figure $2 \mathrm{C})$ than healthy controls.

\subsection{Clinical, coagulation and fibrinolysis biomarker correlations and renal impairment}

Renal function markers eGFR and Cystatin $C$ correlated with urinary lysine levels $(r=.63, P=.03$ and $r=-.64, P=.03$, respectively).
Intriguingly, renal function also correlated with both fibrin formation and fibrinolytic capacity (Table 5). Accordingly, creatinine, eGFR, cystatin C, base excess and bicarbonate levels all correlated with impaired fibrin formation (ODmax), decreased $\alpha 2$-antiplasmin and elevated D-dimer (Table 5) In addition, creatinine correlated negatively with fibrinogen and FIBTEM MCF $(r=-.56, P=.03$ and $r=-.57, P=.03$, respectively), unlike other renal markers.

\section{4 | DISCUSSION}

In clinical management, the bleeding disorder associated with LPI should alert to act appropriately, as upon LPI progression,

TAB LE 3 Haematologic and fibrinolytic variables

\begin{tabular}{|c|c|c|c|}
\hline Variable & \multicolumn{2}{|c|}{ Reference range } & LPI patients \\
\hline \multicolumn{4}{|l|}{ Blood cell count } \\
\hline \multirow[t]{2}{*}{ Haemoglobin (g/L) } & W: & $117-155$ & $123(109-137)$ \\
\hline & M: & $134-67$ & $131(106-147)$ \\
\hline \multirow{2}{*}{$\begin{array}{l}\text { Erythrocytes } \\
\left(10^{12} / \mathrm{L}\right)\end{array}$} & W: & $3.9-5.2$ & $4.3(3.5-4.6)$ \\
\hline & M: & $4.2-5.7$ & $5.0(3.5-5.4)$ \\
\hline \multirow[t]{2}{*}{ Ferritin $(\mu \mathrm{g} / \mathrm{L})$} & W: & $5-100$ & 995 (678-9069) \\
\hline & M: & $10-220$ & 2075 (599-5000) \\
\hline $\begin{array}{l}\text { White blood cells } \\
\left(10^{9} / \mathrm{L}\right)\end{array}$ & & $3.4-8.2$ & $5.3(3.5-10.6)$ \\
\hline Platelets $\left(10^{9} / \mathrm{L}\right)$ & & $150-360$ & $154(95-309)$ \\
\hline \multicolumn{4}{|l|}{ Platelet function } \\
\hline $\begin{array}{l}\text { PFA-epinephrine } \\
\text { (s) }\end{array}$ & & $82-150$ & $179(102-300)$ \\
\hline PFA-ADP (s) & & $62-100$ & $115(102-162)$ \\
\hline \multicolumn{4}{|l|}{ Coagulation markers } \\
\hline VWF:activity (\%) & & $44-183$ & $110(47-211)$ \\
\hline PT (\%) & & $70-130$ & $103(77-160)$ \\
\hline APTT (s) & & $23-33$ & $25(20-29)$ \\
\hline $\mathrm{TT}(\mathrm{s})$ & & $17-25$ & $22(19-30)$ \\
\hline Fibrinogen (g/L) & & $1.7-4.0$ & $2.5(1.0-4.3)$ \\
\hline FXIII (\%) & & $76-156$ & $58(27-141)$ \\
\hline $\begin{array}{l}\text { Prothrombin } \\
\text { fragment } 1+2 \\
(\mathrm{pmol} / \mathrm{L})\end{array}$ & & $53-217$ & $\begin{aligned}> & 1200 \\
& (961->1200)\end{aligned}$ \\
\hline \multicolumn{4}{|l|}{ Fibrinolysis } \\
\hline Plasminogen (\%) & & $80-120$ & $120(91-155)$ \\
\hline$\alpha 2$-antiplasmin (\%) & & $80-120$ & $88(50-105)$ \\
\hline $\begin{array}{l}\text { Plasmin- } \\
\text { antiplasmin } \\
\text { complex }(\mu \mathrm{g} / \mathrm{L})\end{array}$ & & $47-562$ & $>2000$ \\
\hline D-dimer (mg/L) & & $<0.5$ & $32(12-109)$ \\
\hline TAFI (\%) & & $64-125$ & $72(48-121)$ \\
\hline
\end{tabular}

PT, prothrombin time; APTT, activated partial thromboplastin time; TT, thrombin time; FXIII, factor XIII; TAFI, thrombin-activatable fibrinolysis inhibitor; W, women; $M$, men.

Data for LPI patients are given as median (range). 
(A)

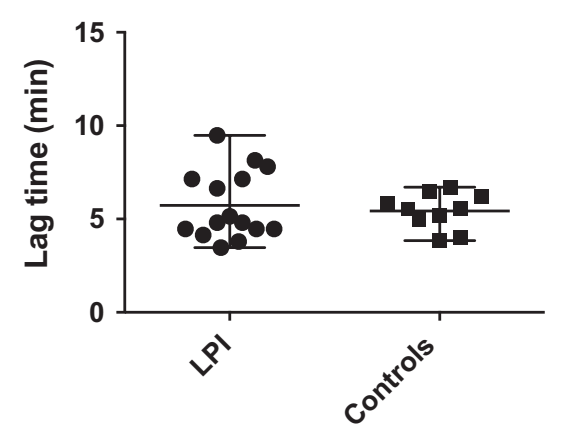

(B)

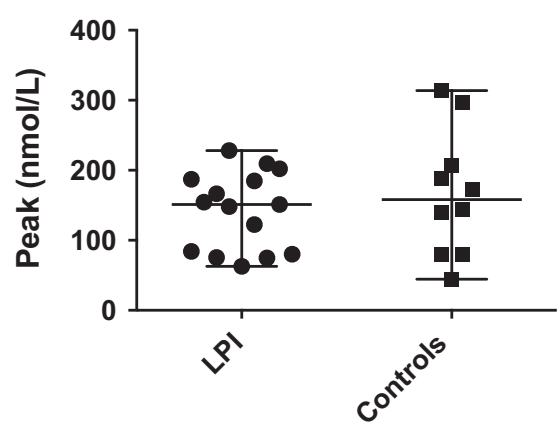

(C)

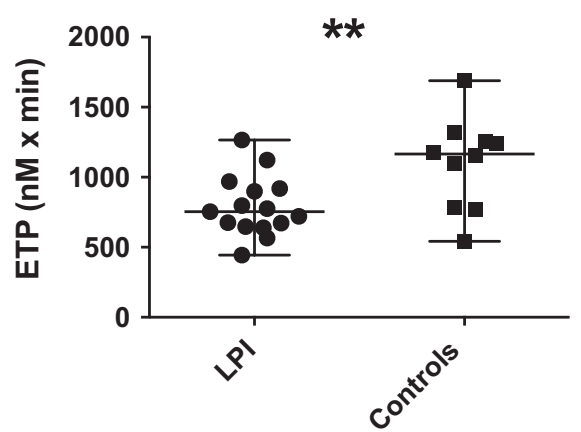

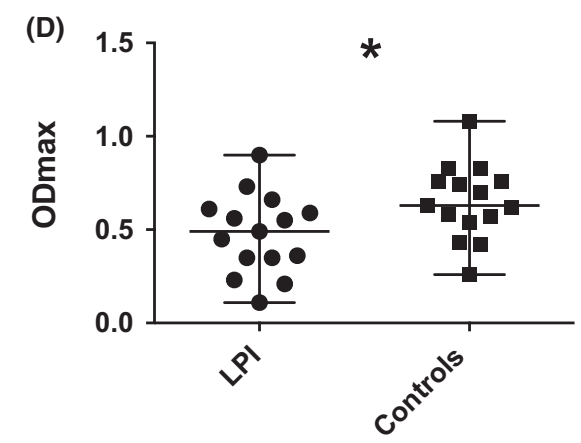

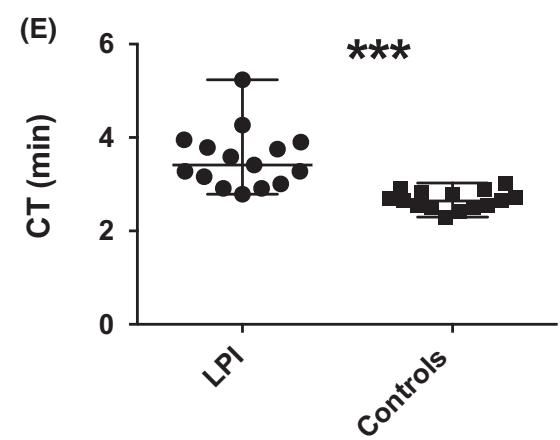

FIGURE 1 Thrombin generation and fibrin clot formation. LPI patients were compared with healthy controls. The median lag time (A), in Calibrated Automated Thrombogram (CAT) was $4.8 \mathrm{~min}$ (range 3.5-9.5 min) vs control $5.6 \mathrm{~min}$ (range 3.8-6.7 min) (not significant between the groups, NS). CAT median peak thrombin generation (B), was $150 \mathrm{nmol} / \mathrm{L}$ (range $60-230 \mathrm{nmol} / \mathrm{L}$ ), while in control, it was $160 \mathrm{nmol} / \mathrm{L}$ (range 40-310 nmol/L) (NS). Endogenous thrombin potential (ETP) (C), in CAT was reduced (median $750 \mathrm{nmol} / \mathrm{L} / \mathrm{min} ; \mathrm{range} 440-1270 \mathrm{nmol} / \mathrm{L} / \mathrm{min}$ ) vs controls (median 1170; range $540-1690 \mathrm{nmol} / \mathrm{L} / \mathrm{min})(P=.02)$. Fibrin clot formation traced by ODmax was reduced (median 0.49; range 0.110.90 ) vs controls (median 0.63; range 0.26-1.08) $(P=.03)(D)$. ODmax derivative clotting time $(C T)(E)$, was prolonged (median 3.41 min; range 2.79-5.24 min) vs controls (median $2.64 \mathrm{~min}$; range $2.30-3.03 \mathrm{~min})(P<.001)$. Lines represent median and range. ${ }^{*} P=.03,{ }^{* *} P=.02,{ }^{* * *} P<.001$

TA B LE 4 ROTEM

\begin{tabular}{|llcc|}
\hline Variable & ROTEM variables & Reference range & LPI patients \\
\hline EXTEM & CT (s) & $38-79$ & $72(61-213)$ \\
& CFT (s) & $34-159$ & $141(88-425)$ \\
& MCF (mm) & $50-72$ & $52(35-73)$ \\
& ML (\%) & $0-15$ & $1(0-14)$ \\
\hline \multirow{2}{*}{ INTEM } & CT (s) & $100-240$ & $178(149-214)$ \\
& CFT (s) & $30-110$ & $109(59-702)$ \\
& MCF (mm) & $50-72$ & $55(25-73)$ \\
& ML (\%) & $0-15$ & $0(0-14)$ \\
\hline FIBTEM & MCF (mm) & $9-25$ & $9(3-20)$ \\
\hline
\end{tabular}

$\mathrm{CT}$, clotting time; CFT, clot formation time; MCF, mean clot firmness; $\mathrm{ML}$, maximum lysis.

Data for LPI patients are given as median (range).

many patients develop end-stage renal disease, requiring invasive procedures, for example dialysis and renal transplantation. ${ }^{9}$ Mucocutaneous bleeds mainly triggered with invasive and surgical interventions or postpartum are typical. We encountered impaired primary haemostasis and strongly elevated thrombin formation and fibrinolysis activation in vivo, while subsequently the in vitro coagulation responses were attenuated. Based on previous studies and now confirmed by ours, renal insufficiency in LPI associates with lysine loss in urine. ${ }^{27}$ According to our study, markers of abnormal fibrin and enhanced fibrinolysis associated with metabolic abnormalities and renal insufficiency.

Our study carries some limitations. We did not include a matched control group with renal insufficiency to the study design. The complex pathogenesis of renal diseases carries several variants with highly specific alterations in the coagulation and fibrinolytic system, rendering the choice of the potential control group difficult. ${ }^{28}$ Impaired primary haemostasis, ${ }^{29,30}$ hypercoagulability and hypo- as well as hyperfibrinolysis have been described to associate with deteriorating kidney function. ${ }^{31-34}$ However, we observed approximately 20 -fold higher levels of D-dimer in LPI as reported for other patients with chronic kidney disease (CKD) in general ${ }^{31,32}$ while fibrinogen, elevated in CKD, ${ }^{34}$ was low to normal in LPI. One laboratory-related limitation is the absence of the second step of centrifugation during our sample collection, which is recommended for the CAT assay, but the control samples were handled in the same manner.

Kayanoki et $\mathrm{al}^{20}$ have suggested that LPI patients exhibit disseminated intravascular coagulation (DIC) due to reduced nitric oxide production. Our results show elevated levels of F1 + 2, Ddimer, and PAP may indeed support this suggestion. However, 
(A)

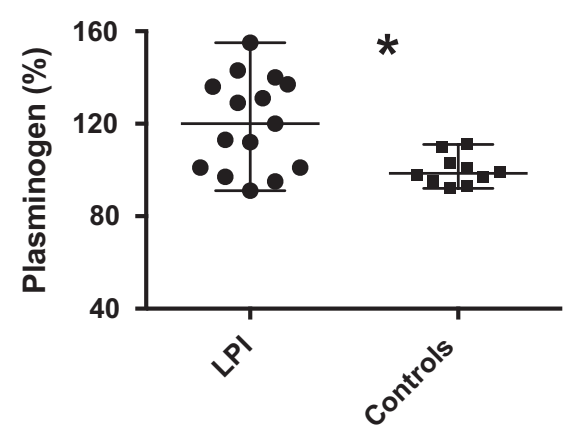

(B)

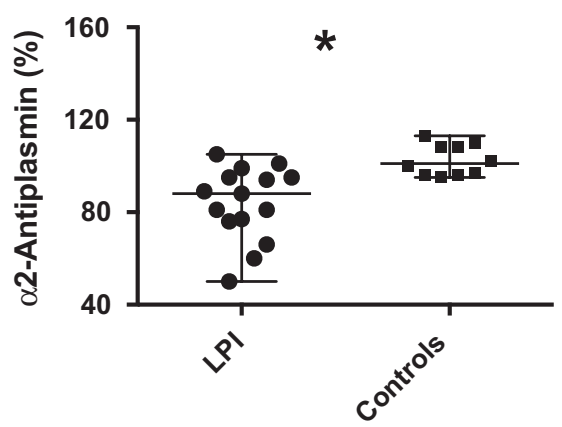

(C)

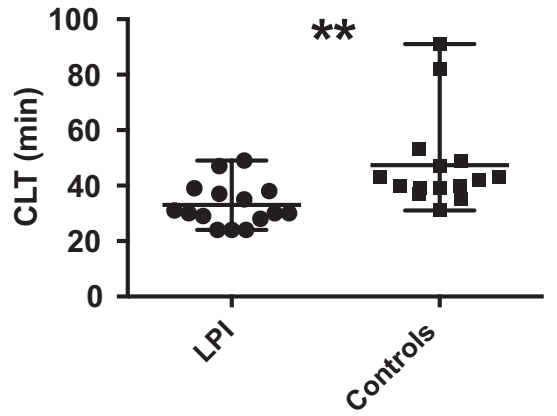

FIG URE 2 Fibrinolysis markers. LPI patients were compared with healthy controls. Median plasminogen (A), in LPI was 120\% (range 91\%$155 \%)(P=.01)$ vs $100 \%$ (range $92 \%-111 \%)$ in controls $(P=.01)$. Median $\alpha 2$-antiplasmin (B), in LPI was $88 \%$ (range $50-105)$ vs $101 \%$ in controls (range 95\%-113\%) $(P<.001)$. Median fibrin clot lysis time (CLT) (C), in LPI was $30 \mathrm{~min}(24-49 \mathrm{~min})$ and 42 min in controls (range $31-91 \mathrm{~min})$ $(P<.01)$. Lines represent median and range. ${ }^{*} P=.01,{ }^{* *} P<.01$

TABLE 5 Renal impairment was associated with coagulation and fibrinolysis activities when calculated with Spearman's correlation

\begin{tabular}{lllllll} 
& & Creatinine & eGFR & Cystatin C & BE & Bicarbonate \\
\hline OD $_{\max }$ & $r:$ & -.87 & .84 & -.82 & .64 & .70 \\
& $P:$ & $<.001$ & $<.001$ & $<.001$ & .02 & .01 \\
\multirow{2}{*}{ D-dimer } & $r:$ & .61 & -.56 & .55 & -.72 & .70 \\
& $P:$ & .02 & .03 & .04 & $<.01$ & .01 \\
$\alpha 2$-antiplasmin & $r:$ & -.69 & .62 & .63 & .75 & .73 \\
& $P:$ & $<.01$ & .04 & .04 & $<.01$ & $<.01$ \\
\hline
\end{tabular}

ODmax, maximum optical density, eGFR, estimated glomerular filtration rate; BE, base excess. thrombocytopenia was mild, and normal PT, APTT and VWF activity exclude significant coagulation factor consumption. Fibrinogen and FXIII levels varied from low to normal. Altered EXTEM and INTEM variables in ROTEM correlated with low fibrinogen levels, but not with platelet counts, suggesting that in LPI poor fibrin formation contributes to impaired clot formation, but the mild thrombocytopenia does not. Our in vitro coagulation assays revealed reduced ETP and prolonged CT. ETP displays thrombin predominantly generated after clot formation, ${ }^{35}$ and the clots formed by low concentrations of thrombin are less resistant to fibrinolysis. ${ }^{36,37}$ Elevated plasminogen/ $\alpha 2$-antiplasmin ratio even further promotes fibrinolysis, ${ }^{38}$ as evidenced by shortened CLT in fibrin generation-clot lysis test. We conclude that impaired primary haemostasis and minor consumption coagulopathy together with enhanced fibrinolysis may explain the bleeding tendency associated with LPI.

We herein suggest an alternative mechanism for the high F1 + 2, $\mathrm{PAP}$, and D-dimer and propose that this may partially reflect impaired hepatic clearance. Although $\mathrm{y}^{+}$LAT-1 is not expressed in liver, hepatic enlargement with relevant histopathological changes is found in the majority of LPI patients. ${ }^{4}$ Indicators of in vivo coagulation (F1 + 2) and fibrinolysis (D-dimer and PAP) are breakdown products or protease-inhibitor complexes with relatively short half-lives. The hepatic clearance of these molecule complexes may be delayed in LPI due to liver involvement, as seen in cirrhosis. ${ }^{39}$ The abovementioned metabolic complexes are highly elevated in LPI, albeit clinical liver disease is not present. In addition, lipid metabolism of combined hyperlipidaemia ${ }^{40}$ further overloads liver in LPI. Further studies are required to ascertain whether impaired hepatic clearance contributes to elevated levels of in vivo indicators of coagulation and fibrinolysis in LPI.

Our LPI patients presented with moderate renal insufficiency, confirmed by elevated creatinine, cystatin $\mathrm{C}$ and urine beta2microglobulin levels. At normal $\mathrm{pH}$, base excess and bicarbonate levels accorded with systemic acidosis due to chronic renal insufficiency and tubular dysfunction via LPI. ${ }^{41}$ Pathophysiological mechanisms of renal impairment in LPI are not fully elucidated, but several explanations have been suggested. Lysine trapped inside the proximal tubular cells causes direct toxicity and apoptosis. ${ }^{27,42}$ Furthermore, oral lysine supplementation in rats promotes proteinuria and inhibits albumin reabsorption by the proximal tubular cells. ${ }^{42}$ According to the second hypothesis, arginine accumulation in renal cells may promote local synthesis of nitric oxide and trigger inflammation and immune system overstimulation, causing immune glomerulopathy. ${ }^{41,43,44}$ The severity of renal insufficiency in LPI correlated with the overt fibrinolysis, as $\alpha 2$-antiplasmin and D-dimer clearly associated with the loss of renal function. During hyperfibrinolysis, altered plasminogen/ $\alpha 2$-antiplasmin ratio may lead to plasminemia, which is harmful to kidneys. ${ }^{45}$ Also, ODmax, a variable derived from fibrin generation tracings, and affected in particular by both the fibrinogen level and the amount of thrombin generated, revealed a significant association with the markers of renal function. 
In addition to routine perioperative coagulation screening, platelet counts and function, fibrinogen, FXIII and D-dimer should be measured in LPI patients, as inadequate activities can be supported with blood products and concentrates. ROTEM was able to identify the patients with the most severe coagulation defect and may, particularly in emergency situations, guide transfusion therapy in LPI patients. The role of tranexamic acid in managing hyperfibrinolysis associated with lysine deficiency is worth studying.

\section{AUTHOR CONTRIBUTION}

R Lassila, H Niinikoski, HJM Brinkman and JCM Meijers were responsible for the study concept and design. H Pitkänen, $M$ Kärki, M Zuurveld, WF Kopatz, M Pikta, L Tanner, K Näntö-Salonen and H Niinikoski were responsible for the acquisition of data. $\mathrm{H}$ Pitkänen and $M$ Kärki were responsible for database handling and updating and for statistical analysis. H Pitkänen, M Kärki, HJM Brinkman and $\mathrm{R}$ Lassila were responsible for drafting the manuscript. H Niinikoski, HJM Brinkman, JCM Meijers and Riitta Lassila were responsible for the interpretation of results. L Tanner, K Näntö-Salonen, H Niinikoski, HJM Brinkman, JCM Meijers and Riitta Lassila were responsible for critical revision of the manuscript for important intellectual content. All authors had full access to all data in the study and take responsibility for the integrity of data and the accuracy of the data analysis.

\section{ACKNOWLEDGEMENTS}

We acknowledge the following collaborators for skilful assistance: Annukka Jouppila and Marja Lemponen from Helsinki University Hospital Research Institute and the nurses and laboratory personnel in Turku University Hospital.

\section{DISCLOSURES}

Riitta Lassila is a member of the Advisory Board of Astra Zeneca, Bayer, CLS Behring, Novo Nordisk, Portola, Shire and Roche. These responsibilities played no role in the study design, in the collection, analysis and interpretation of data, in the writing of the report, or in the decision to submit the report for publication. All other authors stated that they have no competing interests.

\section{ORCID}

H. H. Pitkänen (iD http://orcid.org/0000-0002-2259-3244

\section{REFERENCES}

1. Perheentupa J, Visakorpi JK. Protein intolerance with deficient transport of basic aminoacids. Another inborn error of metabolism. Lancet. 1965;2:813-816.

2. Norio R, Perheentupa J, Kekomaki M, Visakorpi JK. Lysinuric protein intolerance, an autosomal recessive disease. A genetic study of 10 Finnish families. Clin Genet. 1971;2:214-222.
3. Rajantie J, Simell O, Perheentupa J. Basolateral-membrane transport defect for lysine in lysinuric protein intolerance. Lancet. 1980;1:1219-1221.

4. Shinawi M, Dietzen DJ, White FV, Sprietsma L, Weymann A. Earlyonset hepatic fibrosis in lysinuric protein intolerance. J Pediatr Gastroenterol Nutr. 2011;53:695-698.

5. Simell O, Perheentupa J, Rapola J, Visakorpi JK, Eskelin LE. Lysinuric protein intolerance. Am J Med. 1975;59:229-240.

6. Tanner LM, Niinikoski H, Nanto-Salonen K, Simell O. Combined hyperlipidemia in patients with lysinuric protein intolerance. $J$ Inherit Metab Dis. 2010;33(Suppl 3):S145-S150.

7. Lukkarinen $\mathrm{M}$, Parto $\mathrm{K}$, Ruuskanen $\mathrm{O}$, et al. B and T cell immunity in patients with lysinuric protein intolerance. Clin Exp Immunol. 1999;116:430-434.

8. DiRocco M, Garibotto G, Rossi GA, et al. Role of haematological, pulmonary and renal complications in the long-term prognosis of patients with lysinuric protein intolerance. Eur J Pediatr. 1993;152:437-440.

9. Tanner LM, Nanto-Salonen K, Niinikoski H, et al. Nephropathy advancing to end-stage renal disease: a novel complication of lysinuric protein intolerance. J Pediatr. 2007;150:631-634. 634

10. Karki M, Nanto-Salonen K, Niinikoski H, Tanner LM. Urine Beta2Microglobulin Is an Early Marker of Renal Involvement in LPI. JIMD Rep. 2016;25:47-55.

11. Parto K, Kallajoki M, Aho H, Simell O. Pulmonary alveolar proteinosis and glomerulonephritis in lysinuric protein intolerance: case reports and autopsy findings of four pediatric patients. Hum Pathol. 1994;25:400-407.

12. Duval M, Fenneteau O, Doireau $\mathrm{V}$, et al. Intermittent hemophagocytic lymphohistiocytosis is a regular feature of lysinuric protein intolerance. J Pediatr. 1999;134:236-239.

13. Sperandeo MP, Bassi MT, Riboni M, et al. Structure of the SLC7A7 gene and mutational analysis of patients affected by lysinuric protein intolerance. Am J Hum Genet. 2000;66:92-99.

14. Koizumi A, Shoji Y, Nozaki J, et al. A cluster of Iysinuric protein intolerance (LPI) patients in a northern part of Iwate, Japan due to a founder effect. The Mass Screening Group. Hum Mutat. 2000;16:270-271.

15. Borsani G, Bassi MT, Sperandeo MP, et al. SLC7A7, encoding a putative permease-related protein, is mutated in patients with lysinuric protein intolerance. Nat Genet. 1999;21:297-301.

16. Torrents D, Estevez R, Pineda M, et al. Identification and characterization of a membrane protein $(y+L$ amino acid transporter-1) that associates with $4 \mathrm{~F} 2 \mathrm{hc}$ to encode the amino acid transport activity $\mathrm{y}+\mathrm{L}$. A candidate gene for lysinuric protein intolerance. J Biol Chem. 1998;273:32437-32445.

17. Torrents D, Mykkanen J, Pineda M, et al. Identification of SLC7A7, encoding $\mathrm{y}+\mathrm{LAT}-1$, as the lysinuric protein intolerance gene. Nat Genet. 1999;21:293-296.

18. Lek M, Karczewski KJ, Minikel EV, et al. Analysis of protein-coding genetic variation in 60,706 humans. Nature. 2016;536:285-291.

19. Tanner L, Nanto-Salonen K, Niinikoski H, et al. Hazards associated with pregnancies and deliveries in lysinuric protein intolerance. Metabolism. 2006;55:224-231.

20. Kayanoki Y, Kawata S, Yamasaki E, et al. Reduced nitric oxide production by L-arginine deficiency in lysinuric protein intolerance exacerbates intravascular coagulation. Metabolism. 1999;48:1136-1140.

21. Levey AS, Stevens LA, Schmid CH, et al. A new equation to estimate glomerular filtration rate. Ann Intern Med. 2009;150:604-612.

22. Rodeghiero F, Tosetto A, Abshire T, et al. ISTH/SSC bleeding assessment tool: a standardized questionnaire and a proposal for a new bleeding score for inherited bleeding disorders. J Thromb Haemost. 2010;8:2063-2065. 
23. Elbatarny M, Mollah S, Grabell J, et al. Normal range of bleeding scores for the ISTH-BAT: adult and pediatric data from the merging project. Haemophilia. 2014;20:831-835.

24. Lang T, Bauters A, Braun SL, et al. Multi-centre investigation on reference ranges for ROTEM thromboelastometry. Blood Coagul Fibrinolysis. 2005;16:301-310.

25. Hemker HC, Giesen P, AIDieri R, et al. The calibrated automated thrombogram (CAT): a universal routine test for hyper- and hypocoagulability. Pathophysiol Haemost Thromb. 2002;32:249-253.

26. Henter J-I, Horne A, Aricó M, et al. HLH-2004: diagnostic and therapeutic guidelines for hemophagocytic lymphohistiocytosis. Pediatr Blood Cancer. 2007;48:124-131.

27. Verzola D, Fama A, Villaggio B, et al. Lysine triggers apoptosis through a NADPH oxidase-dependent mechanism in human renal tubular cells. J Inherit Metab Dis. 2012;35:1011-1019.

28. Madhusudhan T, Kerlin BA, Isermann B. The emerging role of coagulation proteases in kidney disease. Nat Rev Nephrol. 2016;12:94-109.

29. Islam N, Fulop T, Zsom L, et al. Do platelet function analyzer-100 testing results correlate with bleeding events after percutaneous renal biopsy? Clin Nephrol. 2010;73:229-237.

30. van den Hoogen MWF, Verbruggen BW, Polenewen R, Hilbrands LB, Nováková IRO. Use of the Platelet Function Analyzer to minimize bleeding complications after renal biopsy. Thromb Res. 2009;123:515-522.

31. Lindner G, Funk G-C, Pfortmueller CA, et al. D-dimer to rule out pulmonary embolism in renal insufficiency. Am J Med. 2014;127:343-347.

32. Karami-Djurabi R, Klok FA, Kooiman J, et al. D-dimer testing in patients with suspected pulmonary embolism and impaired renal function. Am J Med. 2009;122:1050-1053.

33. Adams MJ, Irish AB, Watts GF, Oostryck R, Dogra GK. Hypercoagulability in chronic kidney disease is associated with coagulation activation but not endothelial function. Thromb Res. 2008;123:374-380.

34. Mezzano D, Pais EO, Aranda E, et al. Inflammation, not hyperhomocysteinemia, is related to oxidative stress and hemostatic and endothelial dysfunction in uremia. Kidney Int. 2001;60:1844-1850.

35. Mann KG, Brummel K, Butenas S. What is all that thrombin for? J Thromb Haemost. 2003;1:1504-1514.

36. Wolberg AS. Thrombin generation and fibrin clot structure. Blood Rev. 2007;21:131-142.

37. Zucker M, Seligsohn U, Salomon O, Wolberg AS. Abnormal plasma clot structure and stability distinguish bleeding risk in patients with severe factor XI deficiency. J Thromb Haemost. 2014;12: 1121-1130.

38. Reynders J, Rodzynek JJ, Leautaud P, Delcourt A. Fibrinolysis estimated by the plasminogen/antiplasmin ratio in diabetic patients relation to vascular complications and in vivo platelet activation. Front Diabetes. 1987;8:197-199.

39. Lisman T, Leebeek FW. Hemostatic alterations in liver disease: a review on pathophysiology, clinical consequences, and treatment. Dig Surg. 2007;24:250-258.

40. Strickland DK, Ranganathan S. Diverse role of LDL receptor-related protein in the clearance of proteases and in signaling. J Thromb Haemost. 2003;1:1663-1670.

41. Nicolas C, Bednarek N, Vuiblet V, et al. Renal involvement in a French paediatric cohort of patients with lysinuric protein intolerance. JIMD Rep. 2016;29:11-17.

42. ThelleK, Christensen El, Vorum H, Orskov H, Birn H. Characterization of proteinuria and tubular protein uptake in a new model of oral Llysine administration in rats. Kidney Int. 2006;69:1333-1340.

43. Mannucci L, Emma F, Markert M, et al. Increased NO production in lysinuric protein intolerance. J Inherit Metab Dis. 2005;28: 123-129.

44. Nagasaka H, Tsukahara H, Yorifuji T, et al. Evaluation of endogenous nitric oxide synthesis in congenital urea cycle enzyme defects. Metabolism. 2009;58:278-282.

45. Edgtton KL, Gow RM, Kelly DJ, Carmeliet P, Kitching AR. Plasmin is not protective in experimental renal interstitial fibrosis. Kidney Int. 2004;66:68-76.

\section{SUPPORTING INFORMATION}

Additional supporting information may be found online in the Supporting Information section at the end of the article.

How to cite this article: Pitkänen $\mathrm{HH}$, Kärki M, Niinikoski $\mathrm{H}$, et al. Abnormal coagulation and enhanced fibrinolysis due to lysinuric protein intolerance associates with bleeds and renal impairment. Haemophilia. 2018;24:e312-e321. https://doi. org/10.1111/hae.13543 